\title{
Performance in Transverse Direction of Fiber-Reinforced Polymer Bridge Decks
}

\author{
Sonia Yanes, Julia de Castro, Thomas Keller \\ Composite Construction Laboratory, École Polytechnique Fédérale de Lausanne, Switzerland
}

Contact: thomas.keller@epfl.ch

\begin{abstract}
Pultruded glass fiber-reinforced polymer (GFRP) bridge decks distribute punctual vehicular loads to the underlying superstructure and can also act as the upper chord of hybrid main girders. The deck's structural performance in both cases is influenced by its transverse behavior. The static bending behavior in the transverse-to-pultrusion direction of two GFRP bridge deck systems with trapezoidal $(D S)$ and triangular $(A S)$ cell cross-sectional geometry was experimentally studied. Different load transfer mechanisms were found in DS (frame-dominated) and AS (truss-governed) depending on the cell geometry. The $D S$ deck exhibited a lower apparent bending stiffness and degree of composite action between the face sheets than the AS deck, which was attributed to the lower transverse in-plane shear stiffness provided by the trapezoidal core than by the triangular core. The system in-plane shear moduli were estimated from the experimental deflection results.
\end{abstract}

Keywords: GFRP; pultrusion; bridge deck; transverse behavior; in-plane shear modulus; composite action; mechanical testing.

\section{Introduction}

Glass fiber-reinforced polymer (GFRP) bridge decks have been increasingly employed during the last decades in vehicular and pedestrian bridges, both for new construction and rehabilitation purposes, owing to favorable characteristics compared to traditional reinforced concrete (RC) decks, e.g. light weight, corrosion resistance, rapid and easy assembly, short field installation times, and lower life-cycle costs. Based on the manufacturing and assembly process, GFRP decks can be classified into two categories: sandwich and pultruded decks. Sandwich bridge decks are composed of two GFRP face sheets and a lightweight material core (e.g. honeycomb panel, foam, balsa wood). Pultruded deck systems consist of an assembly of hollow profiles manufactured by the pultrusion process and adhesively bonded together to form the slab. Unit profiles with different cell geometries (e.g. triangular, rectangular, trapezoidal) and profile-to-profile joint configurations have been proposed.

Pultruded GFRP decks exhibit orthotropic structural behavior due to material orthotropy and different load-bearing mechanisms in their longitudinal (parallel to pultrusion) and transverse (perpendicular to pultrusion) directions. In the longitudinal and main working direction, the deck system can be considered as a group of contiguous box or I-beams formed by the deck's webs and face sheets. In its transverse direction, the deck's load transfer mechanism depends on the system's cross-sectional geometry, on the characteristics of the web-face sheets junctions and on the joints between adjacent profiles. 
Pultruded bridge decks distribute and transmit loads applied to the bridge to the main girders. The deck's structural performance as a slab and its orthotropy ratio are influenced by the contribution of the transverse-to-pultrusion direction to carrying applied punctual loads. Additionally, pultruded GFRP decks can participate in transferring loads in the bridge's longitudinal direction, acting as the top chord of the main girders when there is sufficient composite action between the girder and the deck. The contribution of the GFRP deck has been proven to be significant in terms of stiffness and strength in GFRP deck-steel/RC beam hybrid members [1, 2]. Furthermore, the participation of GFRP decks as the upper chord of main girders also depends on the shear transmission within the deck itself in the bridge's longitudinal direction, i.e., the deck's transverse direction. The level of composite action within the deck depends on its transverse in-plane shear stiffness and load transfer mechanisms.

Numerous experimental investigations have been conducted, for several pultruded deck systems, to study their global stiffness, strength, failure modes and fatigue performance under vehicular loads. Experimental research has also focused on the characterization of the deck's longitudinal behavior. Few experimental studies are available for the transverse direction however $[3,4]$.

The aim of this work was to experimentally study and compare the static transverse behavior of two pultruded GFRP decks with different crosssectional geometry (trapezoidal and triangular). Symmetric three-point bending experiments up to failure were conducted on simply supported 200mm-wide deck specimens. Stiffness, strength, failure modes and load transfer mechanisms in their transverse direction were investigated. The experimental results were analyzed to obtain the transverse in-plane shear modulus of both systems. The transverse performance of the two systems is compared and discussed.

\section{Experimental investigation}

\subsection{Specimens and materials}

Two pultruded GFRP deck systems with different transverse cross sections were investigated:
DuraSpan (DS) and Asset (AS). The experimental program was conducted on three beams from each deck design. Specimens were labeled DS- $m$, and $A S-m(m=1-3)$ for the $D S$ and the $A S$ series, respectively.

The DS specimens were composed of four unit module profiles (eight cells). Their global length, width and height were 1230, 200 and 194,6 mm, respectively. The $D S$ unit module profile crosssectional geometry comprises two trapezoidal cells formed by vertical and slightly inclined webs connected to the deck's face sheets. The adjacent unit module profiles are bonded along their vertical webs. A tongue-and-groove connection between panels is provided by lip extensions and steps in the face sheets. Detailed dimensions are shown in Figure 1 (a). The DS deck is composed of E-glass fibers embedded in an isophthalic polyester resin. The in-plane material properties for the face sheets and webs are given in Table 1.

(a)

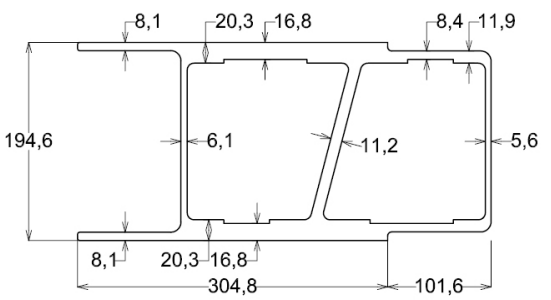

(b)

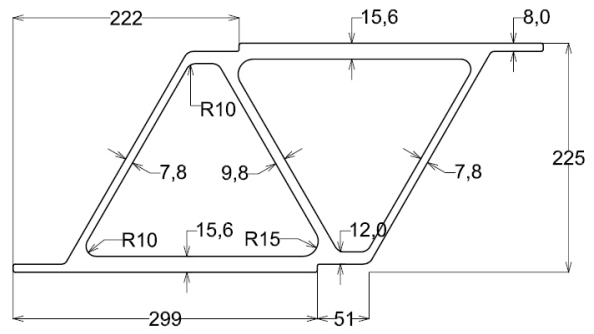

Figure 1. Unit module geometry of (a) DS and (b) AS specimens; dimensions in $\mathrm{mm}$

The AS specimens consisted of seven 200-mmwide unit profiles (fourteen cells). Their global length and height were 2315 and $225 \mathrm{~mm}$, respectively. The cross section of the $A S$ unit profile consists of a parallelogram with an inner diagonal which creates two triangular cells. Dualcell profiles are bonded to the adjacent ones along their outer diagonals. Lip extensions are provided in the face sheets in two of the profile corners and grooves in the two opposite ones in order to facilitate the bonded profile-to-profile connection. The unit shape geometry is depicted in Figure 1 (b). The $A S$ shapes consist of E-glass fibers 
and an isophthalic polyester matrix. The material properties for the face sheets and diagonal elements supplied are given in Table 1.

Table 1. Material properties of DS and AS profiles

\begin{tabular}{|c|c|c|c|}
\hline $\begin{array}{l}\text { Deck } \\
\text { type }\end{array}$ & Element & $\begin{array}{c}\text { Elastic } \\
\text { modulus } \\
E_{X}[\mathrm{MPa}]\end{array}$ & $\begin{array}{c}\text { Elastic } \\
\text { modulus } \\
E_{Y}[\mathrm{MPa}]\end{array}$ \\
\hline \multirow[t]{3}{*}{$D S$} & Face sheets & $21240^{[1]}$ & $\begin{array}{l}11790^{[1]} \\
\left(12980^{(*)}\right)\end{array}$ \\
\hline & Vertical webs & $17380^{[1]}$ & $\begin{array}{r}9650^{[1]} \\
\left(14910^{(*)}\right)\end{array}$ \\
\hline & Inclined webs & $17380^{[1]}$ & $\begin{array}{r}9650^{[1]} \\
\left(16350^{(*)}\right)\end{array}$ \\
\hline \multirow[t]{3}{*}{$A S$} & Face sheets & $27000^{[2]}$ & $19000^{[2]}$ \\
\hline & Outer diagonals & $20000^{[2]}$ & $23000^{[2]}$ \\
\hline & Inner diagonals & $17000^{[2]}$ & $26000^{[2]}$ \\
\hline $\begin{array}{l}X=\text { pultru } \\
\left({ }^{*}\right) \text { Experi }\end{array}$ & $\begin{array}{l}\text { direction, } Y=\text { perpeno } \\
\text { ally obtained for } 0-0 \text {. }\end{array}$ & $\begin{array}{l}\text { lar to pultrusi } \\
\text { \% strain range }\end{array}$ & direction \\
\hline
\end{tabular}

\subsection{Set-up and experimental program}

Both the $D S$ and $A S$ beams were loaded in a threepoint bending configuration. The $D S$ specimens were simply supported on their edges with the supports' axis vertically coinciding with the outer webs' middle plane. The clear span length $L$ was $1210 \mathrm{~mm}$, which corresponds to a span-to-depth ratio of 6,2 . The load was punctually applied at mid-span, on the top of the middle vertical web (see Figure $2(\mathrm{a})$ ). The AS specimens were simply supported with a clear span length $L$ of $1495 \mathrm{~mm}$ (span-to-depth ratio of 6,6 ). The supports were placed under the joints between the $1^{\text {st }} / 2^{\text {nd }}$ and $6^{\text {th }} / 7^{\text {th }}$ specimens' unit shapes. A concentrated load was applied to the specimens' top surface at mid-span, coinciding with the joint area between the $3^{\text {rd }} / 4^{\text {th }}$ profiles (see Figure $2(b)$ ). The load was applied in both experimental series across the beams' whole width.

Specimens were equipped with linear vertical displacement transducers (LVDTs) and electrical strain gages to measure vertical deflections and axial strains along their length (parallel to span), respectively. The mid-span and quarter-span deflections were measured for the $D S$ series on the specimens' bottom face; vertical displace- ments for the AS series were measured at midspan on both the top and bottom faces. Strain gages were placed both on face sheets and webs elements. Pairs of gages were mounted on several sections - one gage on each side. Deflection and strain data were automatically registered at regular intervals by a data acquisition system connected to a computer.

All experiments were performed under displacement control up to failure. The loading rate was $0,05 \mathrm{~mm} / \mathrm{s}$ for the $D S$ specimens and ranged from 0,005 to $0,010 \mathrm{~mm} / \mathrm{s}$ for the AS specimens. Loading-unloading cycles were conducted in both series prior to failure. The cracks' appearance was sketched on the specimens' front surface.

\section{Experimental results}

\subsection{DS beams response}

The load-deflection responses at mid-span $\left(\delta_{1 / 2}\right)$ and quarter-span $\left(\delta_{1 / 4}\right)$ measured for the $D S$ beams are shown in Figure 2 (c). The three beams exhibited linear elastic behavior up to a ca. 7-kN load, when the first audible cracks were heard. No changes in stiffness were observed in the cycles performed prior to reaching that load. The initially linear response turned to nonlinear and the stiffness decreased. Progressive delamination cracking was meanwhile detected in the web-face sheet junctions without causing the specimens' final failure. The sequence of observed cracks in specimens DS-2 and DS-3, their location and the associated load levels are indicated in Figures 2 (a) and 2 (c), on the right side.

Failure, defined as the inability of the specimen to bear any further load increase, occurred at $12,9 / 12,4 / 13,1 \mathrm{kN}$ in specimens $D S-1 / D S-2$ / DS-3, respectively. Noticeable load drops and the development of large displacements were subsequently registered, see Figure 2 (c). The DS beams' failure was governed by local failures in the web-face sheet junctions. Failure occurred due to the propagation of previously formed cracks and subsequent local failure in the top junction of the inclined $8^{\text {th }}$ web, see Figure 3 (a). 
(a)

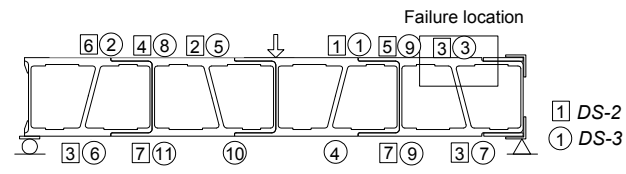

(c)

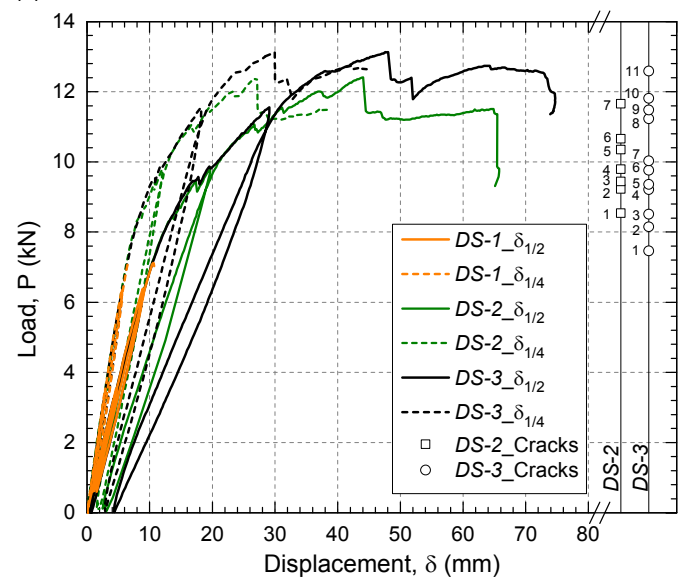

(b)

(d)
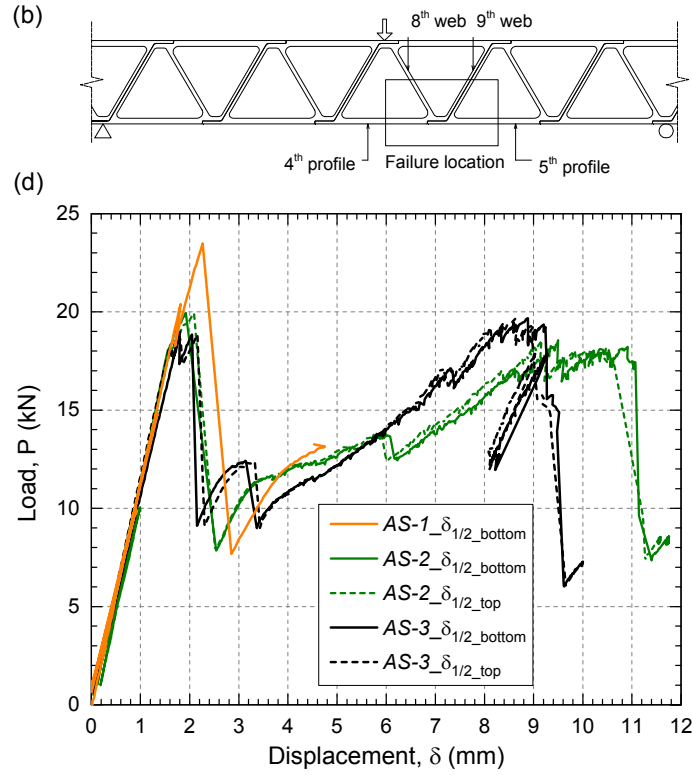

Figure 2. (a) Crack sequence in DS-2 and DS-3; (b) failure location in AS beams; (c) load-deflection behavior of DS beams; (d) load-deflection behavior of AS beams

\subsection{AS beams response}

The load-deflection responses at mid-span registered for the $A S$ beams in their top and bottom faces are shown in Figure 2 (d). The three beams exhibited almost linear elastic behavior until first failure occurred abruptly at 23,5 / 20,0 / 18,8-kN loads for AS-1 / AS-2 / AS-3, respectively. The opening of the adhesive joint in the bottom face sheet between the $4^{\text {th }} / 5^{\text {th }}$ profiles (see Figure $2(\mathrm{~b})$ ) and a crack perpendicular to the $8^{\text {th }}$ web in its bottom part (see Figure $3(b)$ ) were observed at that point for all specimens. Load decreases of $67 / 61 / 52 \%$ were registered for AS-1/AS-2 / AS-3 after the first failure.

Subsequently, all specimens were able to bear an increasing load, however with initial stiffness reductions of between 80 and $85 \%$. Subsequent peaks of 20,8/18,6/19,7-kN loads for AS-1 / AS-2 / AS-3 were reached. The appearance and development of other cracks had meanwhile been observed before final failure took place abruptly. All the beams showed a similar failure pattern with delamination propagating parallel to the adhesive joint between the $4^{\text {th }} / 5^{\text {th }}$ profiles, see Figures 2 (b) and 3 (b).
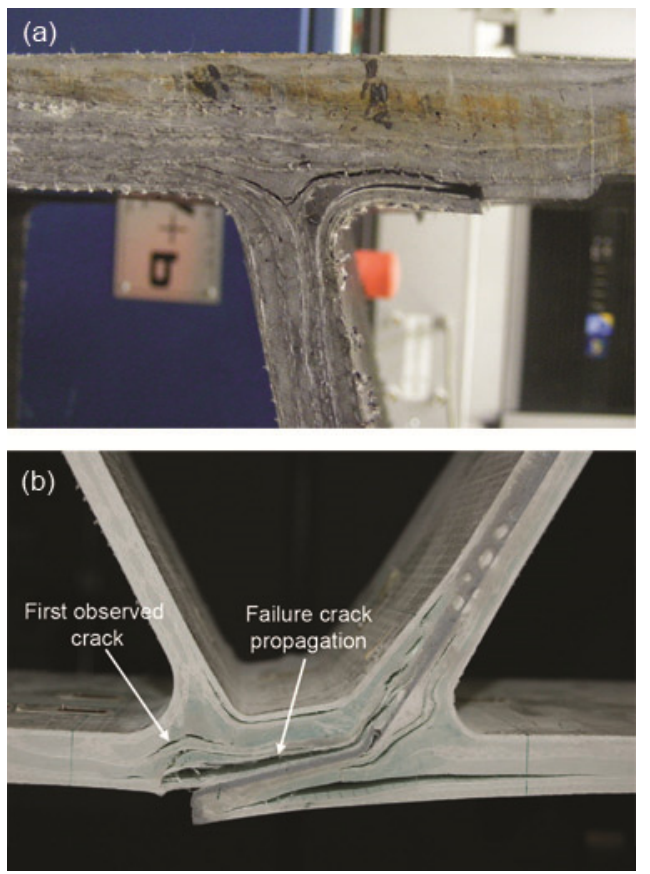

Figure 3. (a) Local failure of specimen DS-1 ( $8^{\text {th }}$ web-top face sheet junction); (b) failure pattern of specimen AS-2 


\section{Comparison of experimental results and discussion}

\subsection{Load transfer mechanisms}

Figure 4 (a) shows the normalized values (strain per unit load) of measured strains in both series during their initial linear behavior. In the $D S$ beams, positive and negative strain values appeared in both the top and bottom face sheets (fs) and in the two instrumented webs. Significant differences in strain data from gages mounted on the same section but opposite surfaces $\left(\varepsilon_{i}, \varepsilon_{j}\right)$ were found. This showed that, in addition to compression (top face sheet, $2^{\text {nd }}$ web) and tension (bottom face sheet, $4^{\text {th }}$ web) axial forces related to truss action, local bending moments and shear forces appeared in the elements. Strains due to local flexural effects, $\varepsilon_{\text {bending, }}$ related to the difference between the $\left(\varepsilon_{i}, \varepsilon_{j}\right)$ values, were significantly higher than strains due to axial forces, $\varepsilon_{\text {axial, }}$, linked to the $\left(\varepsilon_{i}, \varepsilon_{j}\right)$ average value, in the face sheets as well as in the webs. This indicated that the transfer of forces in the DS beams is governed by the frame mechanism (Vierendeel action), with the load transmitted from mid-span to the supports by local bending moment and shear forces in the elements. The calculated $\varepsilon_{\text {bending }} / \varepsilon_{\text {axial }}$ ratios are given in Figure $4(\mathrm{~b})$. $\varepsilon_{\text {bending }} / \varepsilon_{\text {axial }}$ ranged from 1,8 to 39,4 in the face sheets and from 4,2 to 30,3 in the webs for the measured locations in the $D S$ beams.

In the AS beams, mainly positive strain values were recorded in the bottom face sheet and in the single (inner)/ bonded (outer) diagonals of the beams' left/right sides, while predominantly negative strain values were registered in the top face sheet and the bonded/single diagonals of the beams' left/right side, see Figure 4 (a). Absolute normalized strains in the face sheets increased from the supports towards mid-span; on the other hand, comparable values were measured in the bonded or single diagonals in the left and right sides of the beams, independently of their location along the span. Figure 4 (a) shows that the truss mechanism - with increasing tension / compression axial forces in the face sheets towards mid-span and alternatively tensioned / compressed diagonals, with constant axial force - dominated the AS beams' transverse behavior. However, strain measurements showed that local bending moments and shear forces appeared both in the face sheets and the diagonals. Before first failure occurred, $\varepsilon_{\text {bending }} / \varepsilon_{\text {axial }}$ for the instrumented locations ranged from 0,0 to 2,0 , from 0,4 to 1,2 and from 2,0 to 3,0 in the face sheets, single diagonals and bonded diagonals, respectively (see Figure $4(\mathrm{~b})$ ). Slip through the adhesive layer between pairs of gages could however influence this decoupling of strains in the bonded diagonals. The load transfer mechanism did not seem to change significantly after first failure.

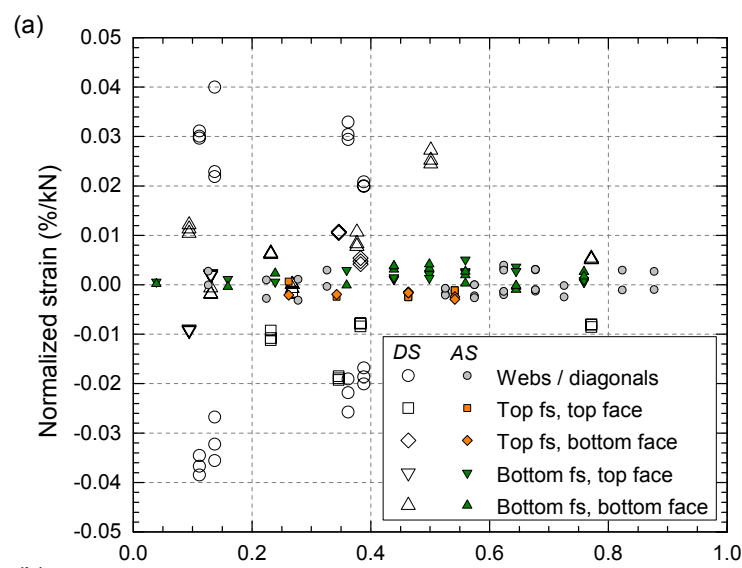

(b)

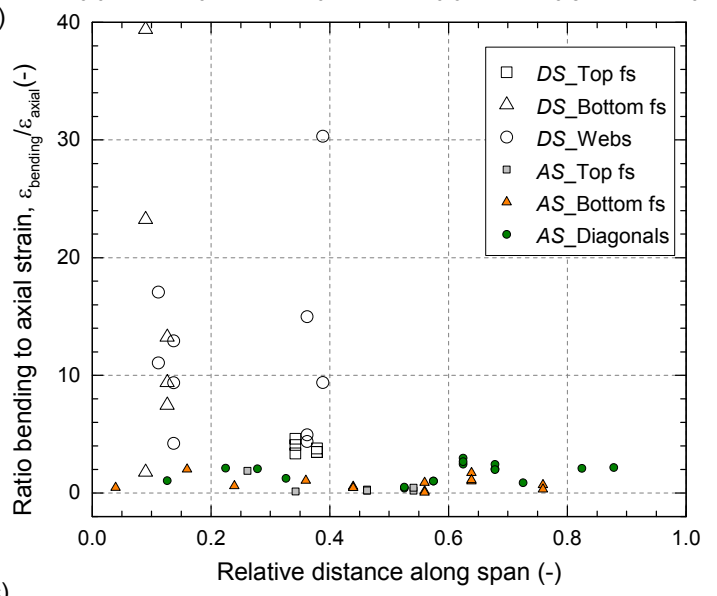

(c)

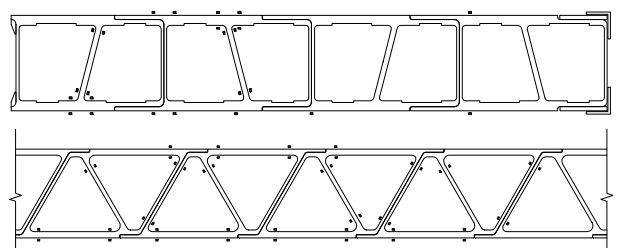

Figure 4. (a) Measured normalized strains; (b) measured ratios of local bending strain to local axial strain; (c) location of strain gages 
Table 2. Calculated apparent bending stiffness

\begin{tabular}{|c|c|c|c|c|c|c|c|}
\hline \multicolumn{4}{|c|}{ DS Deck system } & \multicolumn{4}{|c|}{ AS Deck system } \\
\hline Specimen & $\begin{array}{l}\text { Reference } \\
\text { deflection }\end{array}$ & $\begin{array}{c}E I_{a p p} \\
{\left[\cdot 10^{10} \mathrm{Nmm}^{2}\right]}\end{array}$ & $\begin{array}{c}E I_{\text {app }} / E I_{\text {nom,full }} \\
{[\%]}\end{array}$ & Specimen & $\begin{array}{l}\text { Reference } \\
\text { deflection }\end{array}$ & $\begin{array}{c}E I_{a p p} \\
{\left[\cdot 10^{10} \mathrm{Nmm}^{2}\right]}\end{array}$ & $\begin{array}{c}E I_{a p p} / E I_{\text {nom,full }} \\
{[\%]}\end{array}$ \\
\hline$D S-1$ & $\delta_{1 / 2}$ & 2,7 & $\begin{array}{l}3,6 \\
40\end{array}$ & AS-1 & $\delta_{1 / 2 \_b o t t o m}$ & 75,2 & 57,8 \\
\hline$D S-2$ & $\begin{array}{l}\delta_{1 / 2} \\
\delta_{1 / 4}\end{array}$ & $\begin{array}{l}2,7 \\
3,0\end{array}$ & $\begin{array}{l}3,6 \\
4,0\end{array}$ & $A S-2$ & $\delta_{1 / 2 \text { top }}$ & $\begin{array}{l}77,3 \\
77,3\end{array}$ & $\begin{array}{l}59,4 \\
59,4\end{array}$ \\
\hline$D S-3$ & $\begin{array}{l}\delta_{1 / 2} \\
\delta_{1 / 4}\end{array}$ & $\begin{array}{l}2,7 \\
3,0\end{array}$ & $\begin{array}{l}3,6 \\
4,0\end{array}$ & $A S-3$ & $\begin{array}{l}\delta_{1 / 2 \text { _top }} \\
\delta_{1 / 2 \text { bottom }}\end{array}$ & $\begin{array}{l}80,8 \\
73,8\end{array}$ & $\begin{array}{l}62,1 \\
56,7\end{array}$ \\
\hline
\end{tabular}

\subsection{Apparent transverse bending stiffness and failure load}

The initial apparent bending stiffness $\left(E I_{a p p}\right)$, which includes shear deformation and adhesive joint effects, was derived from the experimental deflection data throughout the specimens' linear behavior range. Linear regression analysis on the measured load-deflection responses and deflection equations of the beam axis from the classical beam theory were used. The calculated initial $E I_{\text {app }}$ values were significantly higher (24 to 30 times) for the $A S$ deck system than for the $D S$ system, see Table 2. The higher $E I_{\text {app }}$ in the AS series than in the $D S$ series was mainly attributed to the influence of the core geometry - triangular vs. trapezoidal. A $19 \%$ higher lever arm between the face sheets (see Figure 1) and a 46-61\% higher transverse elastic modulus in the face sheet laminates (see Table 1) in the AS beams than in the $D S$ beams also contributed.

The $E I_{\text {app }}$ to $E I_{\text {nom,full }}$ ratio isolates the effect of the core geometry in the apparent transverse stiffness of the deck systems. El nom,full represents the nominal bending stiffness of the 200-mm-wide beams, considering the face sheets as beam flanges and assuming full composite action between them. The $E I_{\text {nom,full }}$ values obtained were $74,9 \cdot 10^{10} \mathrm{Nmm}^{2}$ and $130,2 \cdot 10^{10} \mathrm{Nmm}^{2}$ for the DS and $A S$ beams, respectively. The calculated $E I_{\text {app }}$ to $E I_{\text {nom,full }}$ ratios are shown in Table 2 and confirm the effect of the webs' arrangement on the apparent transverse stiffness of the deck. The $D S$ beams showed a negligible degree (less than $4 \%$ ) of composite action between both face sheets while the $E I_{a p p} / E I_{\text {nom,full }}$ values obtained for the $A S$ beams were approximately $60 \%$. The triangular core geometry (AS) provided a significantly higher degree of composite action between the face sheets than the trapezoidal core geometry (DS).

The AS series exhibited 43 to $89 \%$ higher failure loads than the DS series in spite of the 19\% shorter DS-span. Failure occurred in an abrupt manner in the AS beams, whereas it was preceded by a large displacement development in the $D S$ beams. This was attributed to a higher system redundancy in the DS deck (trapezoidal cross section), which exhibited progressive failure in the web-face sheet junctions.

\subsection{Systems' transverse in-plane shear moduli}

In their transverse direction, GFRP pultruded bridge decks can be modeled as two-component (face sheets) composite beams with a flexible shear connection (core). Several design methods exist for composite girders comprising two or more components connected with flexible or partial shear connections. The method developed by Natterer and Hoeft [5] for single-span timberconcrete composite beams was employed in this study. It allows the obtaining of the deflections of the beam, the differential displacement of the two partial cross sections and their internal forces under different loading conditions, based on the cross-sectional geometry, the elastic modulus of the components, the in-plane shear stiffness of the connection and the loading configuration.

The inverse procedure was followed in this study. Experimental load-deflection data, material and geometrical properties were conjointly used with 
the deflection equations to back calculate the inplane shear stiffness - hence $G_{y z}$ - of both deck systems. The bottom face deflections at mid-span $\left(\delta_{1 / 2}\right)$ and quarter-span $\left(\delta_{1 / 4}\right)$ were used separately in the calculations for the $D S$ series. The average mid-span deflection $\left(\delta_{1 / 2 \text { _bottom }}\right.$ and $\left.\delta_{1 / 2 \text { _top }}\right)$ was used for the $A S$ series. The calculated $G_{y z}$ results for $D S$, before any crack was noticed, and for $A S$, before first failure occurred, are shown in Figures $5(a)$ and $5(b)$, respectively. Decreasing $G_{y z}$ values with increasing load in the $D S$ series were attributed to the limitations of the procedure used to register the damage onset based on visual observation. The effect of the face sheets' shear deformation, which is not considered in the aforementioned method, has not been eliminated from the deflection data. The given $G_{y z}$ values therefore constitute a lower bound of the actual in-plane shear moduli.
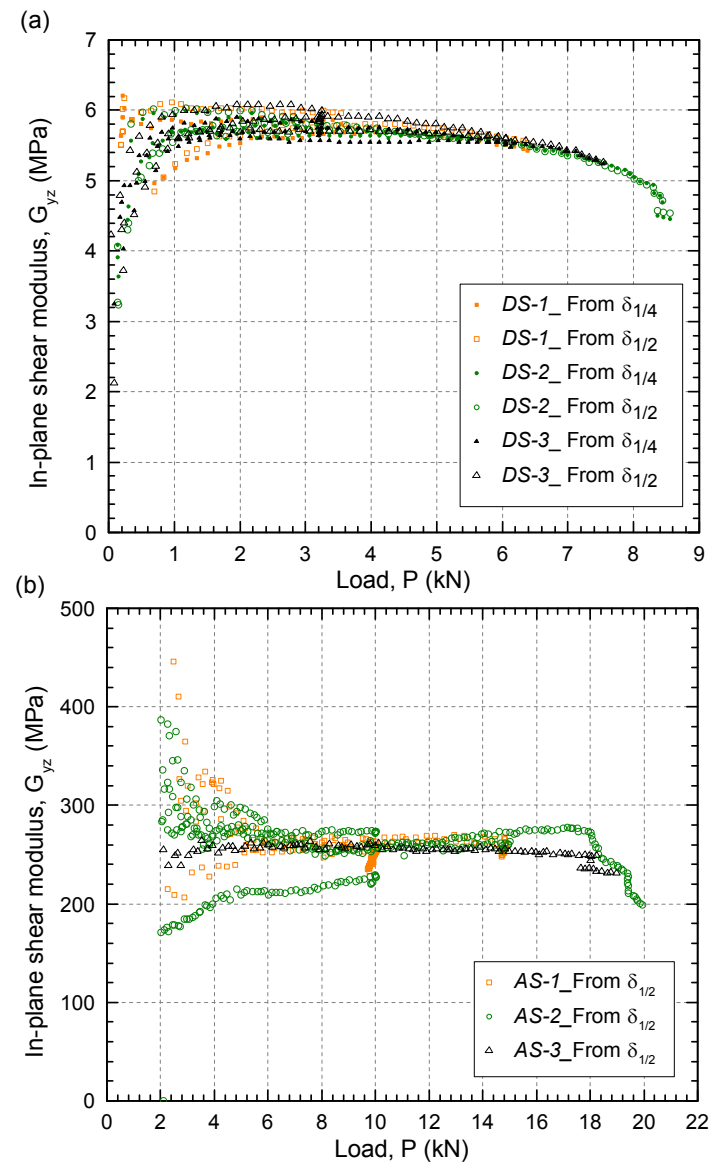

Figure 5. Calculated transverse system in-plane shear modulus for (a) DS series and (b) AS series

The system in-plane shear modulus of the $D S$ beams (approximately 5,5 to $6 \mathrm{MPa}$ ) represented
2-3\% of the modulus of the AS beams (ca. 250$280 \mathrm{MPa}$ ), which is in accordance with the results discussed in Section 4.2. The AS triangular cell cross-sectional geometry provided a significant degree of composite action between the bottom and top face sheets, while the degree of composite action in the DS beams, with trapezoidal-cell cross section, was considerably lower.

\section{Conclusions}

The static transverse behavior of two GFRP pultruded bridge deck systems with different cross-sectional geometry (trapezoidal DS and triangular $A S$ ) was experimentally studied. Three beams from each series were investigated under symmetric three-point bending to evaluate their stiffness, strength, failure modes and load transfer mechanisms. The following conclusions may be drawn from this work:

- The DS deck system exhibited initial linear elastic behavior up to ca. $55 \%$ of the failure load followed by nonlinear behavior. The latter was caused by progressive cracking in the web-flange junctions prior to final failure. The AS deck system exhibited linear elastic behavior up to first failure, which occurred abruptly. Subsequently, comparable peak loads were achieved with decreased stiffness.

- Load transfer mechanisms in the transverse direction differed in the $D S$ and $A S$ specimens and depended on their cross-sectional geometry. Frame behavior was more dominant in the $D S$ system (trapezoidal cells) than in the AS system (triangular cells), which was truss-governed.

- The DS deck system exhibited a significantly lower apparent bending stiffness in its transverse direction than the $A S$ deck system (24 to 30 times less) due to the considerably lower in-plane shear stiffness provided by the trapezoidal (DS) compared to the triangular (AS) core geometry.

- The low bound values for the DS and AS decks' system in-plane shear moduli in their transverse direction were estimated from the experimental deflection results using existing equations for timber-concrete composite beams with flexible shear connections. The DS deck system showed 
substantially lower values than the AS deck system (the thus calculated system in-plane shear modulus of DS represented ca. 2-3\% of the modulus of $A S)$.

\section{References}

[1] Gürtler HW. Composite action of FRP bridge decks adhesively bonded to steel main girders [PhD thesis]. Switzerland: École Polytechnique Fédérale de Lausanne; 2004.

[2] Sebastian W., Gegeshidze G., and Luke S. Positive and negative moment behaviours of hybrid members comprising cellular GFRP bridge decking epoxy-bonded to reinforced concrete beams. Composites Part B: Engineering. 2013; 45(1): 486-496.

[3] Park KT., Kim SH., Lee YH., and Hwang YK. Pilot test on a developed GFRP bridge deck. Composite Structures. 2005; 70(1): 48-59.

[4] Zi G., Kim BM., Hwang YK., and Lee YH. An experimental study on static behavior of a GFRP bridge deck filled with a polyurethane foam. Composite Structures. 2008; 82(2): 257-268.

[5] Natterer J., and Hoeft M. Zum Tragverhalten von Holz-BetonVerbundkonstruktionen. Switzerland: École Polytechnique Fédérale de Lausanne; 1987. Research Report No.: 1345. 